http://jmscr.igmpublication.org/home/

ISSN (e)-2347-176x ISSN (p) 2455-0450

crossref DOI: https://dx.doi.org/10.18535/jmscr/v7i7.107

Journal Of Medical Science And Clinical Research

IGM Publication

An Official Publication of IGM Publication

\title{
Comparison of procedure and predictability between WHO partogram and Paperless Partogram
}

\author{
Authors \\ Dr Deepak Kumar Giri¹, Prof Dr Lalmohan Nayak², Dr Dillip Kumar Dalai* \\ ${ }^{1}$ Assistant Professor, Medinapore Medical College \\ ${ }^{2}$ Professor and HOD, ${ }^{3}$ Junior Resident \\ Dept. of Obstetrics and Gynaecology, VSSIMSAR Burla Odisha \\ *Corresponding Author \\ Dr Dillip Kumar Dalai \\ Junior Resident, Dept. Of obstetrics and Gynecology VSSIMSAR Burla, India
}

\begin{abstract}
WHO partogram, is cumbersome and time consuming procedure for overburdened Indian labour room setup very few clinicians use it. To circumvent the above problem Debdas (2006) introduced a very simple almost timeless mental method called 'Paperless Partogram' which is based on Friedman's rule.

Objectives: Assessment of procedural difference, predictability of 'time' of delivery, user friendliness and fetal outcome between WHO and Paperless partogram

Material: Any uncomplicated patient irrespective of age and parity in spontaneous onset labour with cephalic presentation who is at least $4 \mathrm{~cm}$ dilated carrying pregnancy of 37 completed week

Method: In paperless group, right at first PV the Expected TIME of delivery (ETD) was calculated by mentally adding to the time-point of $P V$ - the number cm left to full dilatation using Friedman's formula of cervical dilatation of $1 \mathrm{~cm} / \mathrm{hour}$. Birth attendant has to add 4 hours to the alert ETD to get 'Action ETD'. Both the ETDs were written in the front of case sheet for everybody's attention. In WHO group PV was done 2 hourly and plotted on graph in usual way.

Results: Around $75 \%$ of cases of both group wereage ranged between 25-30 years, primipara and of gestation between 38-40 weeks. Vaginal delivery occurred in: WHO-87\%, Paperless-89\%. One minute Apgar: WHO-97\%, Paperless-96\% - highly comparable. Even the augmentation rate (74\% in Paperless, $77 \%$ in WHO group) and NICU admission rate (1.4\% in paperless, $1.62 \%$ ) were also comparable.

The only difference found was in 'user friendliness'. While in Paperless group 100\% became fan of the method, $96 \%$ of WHO group expressed that they would like to switch to paperless method, only $4 \%$ were not sure.

Conclusion: Paperless Partogram is 1) equally effective and efficient as the WHO method as a labour management tool, 2) The great point about it is-it is highly user friendly and hence ideal for resource poor situations.
\end{abstract}

\section{Introduction}

The partogram has different variables (fetal. heart rate, dilation of the cervix, contractions, and pulse rate of the mother) plotted on pre-printed paper.
The partogram has been heralded as one of the most important advances in modern obstetric care. The WHO advocates its use as a necessary tool in the management of labor and recommends it's universal use during labor. 
However, some healthcare practitioners, especially in high-income countries, have questioned its effectiveness. In spite of the effort to implement the composite partograph, efforts have sensibly failed in its actual utilization.

Though WHO Partogram has extensive parameters for patient monitoring and evaluation but it is not popular among the busiest Indian physicians where the doctor patient ratio is not even comparable with standard WHO guidelines. Laboring mother may not even a get a labour table in some of the busiest hospital of this country.

With the view to evolve simple user friendly system for centers with high delivery rates and shortage of trained staff Dr A.K. Debdas 2006(India) has developed the "Paperless Partograph" and is widely quoted in the net. This concept of "ETD" constitutes the main software on which 'Paperless Partogram' is based.

\section{Aim of the study}

The purpose of this study is to evaluate:

1) Whether the concept of Paperless partogram is comparable with WHO partogram for assessment of labour.

2) Assessment of procedural difference, predictability of 'time' of delivery, user friendliness and fetal outcome between WHO and Paperless partogram.

\section{Material}

A total 185 (Paperless Partogram is used in 105 cases \& Modified WHO Partogram is used in 80 cases) antenatal women at 37 to 42 weeks of gestational age with, uncomplicated, singleton pregnancy with vertex presentation in spontaneous labour, admitted for safe confinement in labour unit at VSSIMSAR, Burla, Sambalpur, Odisha, between December 2016 to November 201, are included in the study.

\section{Inclusion Criteria}

All women with uncomplicated, singleton \& vertex presentation at 37 to 42 weeks of gestational age in spontaneous labour, were included in the study.

\section{Exclusion Criteria}

* Cephalo pelvic disproportion

* Antepartum haemorrhage

* Severe Pre eclampsia/ eclampsia

* Anemia- $\mathrm{Hb}<9$ grn/ dl

* Malpresehtations

* Multiple pregnancy

* Previous Caesarean section

* Preterm labour

* Fetal distress

* Intrauterine death

* All cases of induced labour

\section{Method}

In paperless group, right at first PV the Expected TIME of delivery (ETD) was calculated by mentally adding to the time-point of PV - the number $\mathrm{cm}$ left to full dilatation using Friedman's formula of cervical dilatation of $\mathbf{1} \mathbf{c m} / \mathbf{h o u r}$. Birth attendant has to add 4 hours to the alert ETD to get 'Action ETD'. Both the ETDs were written in the front of case sheet for everybody's attention. In WHO group PV was done 2 hourly and plotted on graph in usual way.

The clinicians calculated twice - an ALERT ETD (estimated time of delivery) and an ACTION ETD.

The ALERT calculation uses Friedman's widely accepted rule that cervix dilates $1 \mathrm{~cm} / \mathrm{hr}$, while a woman is in active labour (ie when cervix is dilated to $4 \mathrm{~cm}$ or more), e.g. if in a case the cervix is $4 \mathrm{~cm}$ dilated at $2 \mathrm{pm}$, her ETD would work out as $2 \mathrm{pm}+6$ hours $=8$ PM. Assuming that she would take $6 \mathrm{hrs}$ to dilate the remaining $6 \mathrm{~cm}$ to become $10 \mathrm{~cm}$.

The clinician adds four hours to the ALERT ETD to get the ACTION ETD.

Both the ETDs should be written in big bold letters on front page of the woman's case sheet.

The ACTION ETD is to be circled in red.

\section{Frequency of PV examination}

WHO Gr: 2 hourly \& plotted on partograh to produce a graph 
Paperless Gr: Doing PV is generally avoided and done SOS only \&recorded in a self revealing 'Mini Chart' as shown

\section{Observation}

- Residence - Rural, around 80\% (both Gr)

- Education- Literate, around 60\% (both Gr)

- Had some ANC - 60\% (both Gr)

- Overall age distribution:

1. Teen $(16-19 \mathrm{yrs})-15 \%$,

2. Above $30-6 \%$,

3. $20-29-79 \%$

- Overall Parity - $70 \%$ were primi

- Overall distribution of Gest age - $96 \%$ of both Groups fell between 37 and 39 weeks

- Average duration of Active phase (up to the time of del) -4 hours 45 mins

\section{(both Gr considered-were similar)}

- Proportion of cases that crossed Alert ETD line -

1. $\mathrm{WHO} \mathrm{Gr}-19 \%$

2. Paperless $\mathrm{Gr}-20 \%$

- Action ETD (4 hours) time/line but still delivered Vaginally -

1. WHO $\mathrm{Gr}-4$ cases $(2.8 \%)$

2. Paperless $\mathrm{Gr}-6$ cases $(3.0 \%)$

- Apgar Score at 1 minute

1. In both the groups around $96 \%$ New-born scored between 7 and 10

- Distribution of Birth weight of Newborns (in round Fig)

1. Weight under $2.5 \mathrm{Kg}$
a) $\mathrm{WHO} \mathrm{Gr} \quad-15 \%$
b) Paperless Gr - 20\%

- Weight between $2.5-3.5 \mathrm{Kg}$

a) $\mathrm{WHO}-73 \%$

b) Paperless - $73 \%$

- Weight above $3.5 \mathrm{Kg}$

$\begin{array}{ll}\text { WHO Gr } & -8 \% \\ \text { Paperless Gr } & -7 \%\end{array}$

Analysis of user friendliness

$100 \%$ of Birth Attendants of both the groups which included both Nurses and doctors expressed, given choice, they would prefer to use Paperless method

\section{Summery \& Conclusion}

I. Use of 'Paperless partogram' for monitoring Active phase of labor is as efficient as the WHO partogram for low risk cases

II. However, its great plus point is - it is highly User Friendly

\section{References}

1. Friedman EA. Primigravid labour. A graphic statistical analysis. Obstetrics and Gynecology, 1955;6(6):567-89.

2. World Health Organization. The application of the WHO par. tograph in the management of labour. Report of a WHO multicéntre study1990-91. Maternal Health and Safe Motherhood Programme, Geneva, 1994 (WHO document WHO/FHE/IVISM/94.4).

3. World Health Organization. World Health Organization partograph in management of labour. Lancet, 1994;343:1399-1404.

4. Zupan J. Perinatal mortality in developing countries. N Engi J Med. 2005;352:20478. [PubMed]

5. Geneva World Health Organization, 2007 Maternal mortality m 2005 Estimates developed by WHO, UNICEF, UNFPA and the World Bank.

6. Friedman E. Graphic analysis of labor. Am J Obstet 2. Gynecol. 1954;68:1568-75. [PubMed]

7. Philpott RH, Castle WM. Cervicographs in the management of labour in primigravidae. J Obstet Gynaecol $\mathrm{Br}$ Commonw. 1972;79:592-. 8. [PubMedi

8. WHO. World Health Organization partograph in management of labour. Lancet. 1994;343:1399-404.[PubMed]

9. Groeschel N, Clover P. The partograph. Used daily but rarely questioned. Aust J Midwifery. 2001;14:22-7. [PubMed] 
10. Lavender T, Malcohnson L. Is the partogram a help or a hindrance? Pract Midwife. 1999;2:23-7.[PubMed]

11. Walraven GE. WHO partograph. Lancet. 1994;344:617. [PubMed]

12. Lavender T, Hart A, Smyth RN/I. Effect of partogram use on outcomes for women in spontaneous labour at term. Cochrane Database Syst Rev. 2008:CD005461. [PubMed]

13. Debdas AK. Paperless partogram. 41st Annual Scientific Sessions 2008: Sri Laitka College of Obstetrics and Gynaecolcigists. SLJOG vol. 30. 2008;1:124. 